\title{
Findings from the latest National Diet and Nutrition Survey
}

\author{
Gillian Swan \\ Nutrition Division, Food Standards Agency, Aviation House, 125 Kingsway, London WC2B 6NH, UK
}

\begin{abstract}
The National Diet and Nutrition Survey (NDNS) of adults aged 19-64 years, carried out in $2000-1$, is part of the NDNS programme, a series of cross-sectional surveys aiming to provide detailed quantitative information on the diet, nutritional status and related characteristics of the British population. The programme is split into four surveys of different population age-groups, conducted at approximately three-yearly intervals. In the survey of adults food consumption data were collected from 1724 respondents using a $7 \mathrm{~d}$ weighed-intake dietary record. Other components included: height, weight, waist and hip circumference and blood pressure measurements; a $24 \mathrm{~h}$ urine sample; a blood sample; a record of physical activity. Results have been published in four volumes covering food consumption, energy and macronutrient intakes, micronutrient intakes and nutritional status, including physical measurements and physical activity. The results have shown that, based on a comparison of nutrient intakes with the UK dietary reference values, adults in Britain are generally getting sufficient nutrients from their diets. However, younger adults (particularly women) and those in lower socio-economic groups are more likely to have low micronutrient intakes and lower levels of some nutritional status indices. The proportion of food energy derived from total fat has fallen since the last survey of this age-group in 1986-7 and is close to the dietary reference value, while the proportion of energy derived from saturated fatty acids and non-milk extrinsic sugars exceeds the dietary reference values. The prevalence of overweight and obesity has increased since 1986-7 and physical activity levels are low.
\end{abstract}

National Diet and Nutrition Survey: Food consumption: Energy and macronutrient intakes: Micronutrient intakes: Nutritional status

\section{Background}

The present paper reports the findings of the British National Diet and Nutrition Survey of adults aged 19-64 years (Henderson et al. 2002, 2003a,b; Ruston et al. 2004). This survey is part of the National Diet and Nutrition Survey (NDNS) programme, a series of crosssectional surveys of different population age-groups. The programme was set up by the Ministry of Agriculture, Fisheries and Food and the Department of Health in 1990 following the success of the Dietary and Nutritional Survey of British Adults (Gregory et al. 1990), the first survey of this type. The programme is now jointly funded and managed by the Food Standards Agency and Department of Health. It is split into four separate surveys, each conducted at about three-yearly intervals. Each survey has examined a nationally representative sample drawn from four different population age-groups: children aged 1.5-4.5 years (Gregory et al. 1995), young people aged 4-18 years (Gregory et al. 2000), people aged $\geq 65$ years (Finch et al. 1998) and adults aged 19-64 years. Each survey collects detailed quantitative information on food consumption and nutrient intakes, physical measurements, nutritional status indices and socio-economic, demographic and lifestyle characteristics. The results of NDNS provide baseline information on the diet and nutritional status of the population, used by the government as a basis for the development and targetting of evidencebased nutrition policies. The detailed quantitative information collected on food consumption is also used for assessing exposure to food chemicals, allowing the Food Standards Agency to make risk assessments in relation to food chemical safety. The NDNS datasets are deposited at the UK Data Archive (www.data-archive.ac.uk), from where they are available to researchers to conduct their own analyses.

\footnotetext{
Abbreviations: DRV, dietary reference values; LRNI, lower RNI; NDNS, National Diet and Nutrition Survey; RNI, reference nutrient intake. Corresponding author: Gillian Swan, fax +44 207276 8906, email gillian.swan@ foodstandards.gsi.gov.uk
} 


\section{Methodology}

Fieldwork for the NDNS of adults aged 19-64 years took place over 12 months between July 2000 and June 2001, following a feasibility study in 1999. The components of the survey were: a face-to-face interview to collect information on socio-demographic and lifestyle characteristics; a $7 \mathrm{~d}$ weighed-intake dietary record, with estimated portion sizes for foods eaten outside the home; physical measurements: height; weight; waist and hip circumferences; a blood pressure measurement; a $24 \mathrm{~h}$ urine collection, primarily to assess Na intake; a venous blood sample, collected with the respondent's written consent and analysed for a range of indices of nutritional status; a $7 \mathrm{~d}$ record of physical activity; a self-count of the number of teeth and amalgam fillings.

\section{Response}

The $7 \mathrm{~d}$ weighed-intake dietary records were collected from 1724 respondents, a response rate of $47 \%$ of the eligible sample. Blood samples were collected from 1347 respondents, equivalent to $36 \%$ of the eligible sample, and $74 \%$ of those who completed dietary records. The response rate for the dietary record was lower than expected and lower than in previous NDNS. An independent evaluation of the potential impact of non-response bias in the survey data was undertaken by the University of Southampton (Skinner \& Holmes, 2002). The authors concluded that on the basis of the limited information available on nonresponders there was no evidence to suggest serious non-response bias. However, this conclusion should be interpreted with caution as little information was available on refusals and non-contacts. The data were weighted to correct for biases as a result of lower sampling probabilities and lower levels of response by, in particular, men and young adults.

\section{Under-reporting}

Under-reporting of food consumption is a well-recognised phenomenon common to dietary surveys worldwide and has been identified in other NDNS (Finch et al. 1998; Gregory et al. 2000). A doubly-labelled water validation study was carried out as part of the feasibility study for the survey. Estimates of energy intake using the $7 \mathrm{~d}$ weighed dietary record methodology were compared with measurements of energy expenditure using the doubly-labelled water methodology in a small sample of sixty-six subjects (Office for National Statistics, 2002). The results showed that energy intake estimates were below total energy expenditure estimated from doubly-labelled water analysis, and indicated that energy intakes were under-reported on average by $25 \%$. As part of the fieldworker training before the main survey, greater emphasis was placed on the importance of checking the dietary records and probing for missing information in order to improve the quality and completeness of the information. However, it remains likely that intakes reported in the main survey are underestimates, although the extent of any under-reporting is unknown. No attempt has been made to 'correct' the food consumption and nutrient intake data for underreporting, or to exclude 'under-reporters' from the dataset.

\section{Analysis and reporting of the data}

The survey findings have been published as a series of five volumes. The first volume, published in December 2002, covers types and quantities of food consumed (Henderson et al. 2002). The second and third volumes, published in July 2003, cover intakes of energy and macronutrients (Henderson et al. 2003a) and micronutrient intakes and urinary analytes (Henderson et al. 2003b). The fourth volume covering the nutritional status, physical measurements and physical activity levels of the participants was published in February 2004 (Ruston et al. 2004) and a fifth summary volume will complete the series later in 2004.

Results are presented for men and women in four age bands: 19-24 years; 25-34 years; 35-49 years; 50-64 years. Nutrient intakes are compared with UK dietary reference values (DRV) and nutritional status indices are compared with reference values where these were available. Analyses are also presented for four standard regions (Scotland; northern England; central, south-west England and Wales; London and south-east England) and for household receipt of benefits (individuals living in households in which one or more members were in receipt of state benefits).

\section{Results \\ Food consumption}

Respondents were asked as part of the interview whether they were dieting to lose weight at the time of the survey and whether they considered themselves to be vegetarian or vegan. Approximately one-quarter of women (24\%) and $10 \%$ of men reported that they were dieting to lose weight. There was no variation by age. Of the women and men 7 and $2 \%$ respectively said that they were vegetarian or vegan; about half this group reported avoiding fish. The percentage of women who reported being vegetarian or vegan increased to 12 for those aged 19-24 years and 11 for those aged 25-34 years.

Consumption of fruit and vegetables was analysed according to the definition used in the government's 'Five a day' programme (Department of Health, 2002a) and using a portion size of $80 \mathrm{~g}$. Average daily consumption of fruit and vegetables was 2.7 portions for men and 2.9 portions for women, well short of the 'five a day' recommendation. Of the men and women 13 and $15 \%$ respectively met the recommendation, consuming five or more portions per $\mathrm{d}$. Of the men and women 21 and $15 \%$ respectively reported eating no fruit in the survey week, while $2 \%$ ate no vegetables and $1 \%$ reported eating no fruit or vegetables. Mean daily consumption was lowest in the youngest group (19-24 years) at 1.3 and 1.8 portions for men and women respectively and was highest in the oldest group (50-64 years) at $3 \cdot 6$ and $3 \cdot 8$ portions.

Oily fish consumption (excluding canned tuna) was $53 \mathrm{~g}$ per week on average (approximately one-third of a portion); an increase from $34 \mathrm{~g}$ per week on average in 
1986-7, but still well below the government recommendation of one portion per week (Food Standards Agency, 2004). In the oldest women mean consumption had increased from an average of $38 \mathrm{~g}$ per week in 1986-7 to $86 \mathrm{~g}$ in the present survey.

Consumption of soft drinks had approximately doubled overall compared with the 1986-7 survey; mean consumption in 2000-1 was 1.7 litres per week for men and 1.4 litres per week for women, equivalent to about four to five cans. The soft drink consumption of the youngest group was three times as much as that of the oldest group. The majority of soft drinks consumed were carbonated. Women consumed on average similar amounts of diet and non-diet varieties while men consumed almost twice as much of the non-diet type.

\section{Energy and macronutrient intakes}

Table 1 summarises the mean intakes of energy and macronutrients. Mean energy intakes are shown as a percentage of the estimated average requirement (Department of Health, 1991). The mean daily total energy intake was $9 \cdot 72 \mathrm{MJ}(2313 \mathrm{kcal})$ for men and $6.87 \mathrm{MJ}(1632 \mathrm{kcal})$ for women. There was a wide range of energy intakes in each age-group and gender group, with intakes at the upper $2 \cdot 5$ th percentile about two to three times higher than those at the lower $2 \cdot 5$ th percentile. Mean energy intakes fell below the estimated average requirement for each agegroup and gender group and, overall, were $92 \%$ of the estimated average requirement for men and $85 \%$ for women. This finding is in line with other NDNS data (Finch et al. 1998; Gregory et al. 2000). The main food source of energy intake was cereals and cereal products (including biscuits, buns, cakes and pastries), which provided on average about one-third of the energy intake. Meat and meat products contributed a further $15 \%$ of the energy intake, and milk and milk products and drinks (including alcoholic drinks) each contributed 10\%. The mean energy intake for men in this survey was markedly lower than that in the 1986-7 survey (10-30 MJ), while the mean intake for women was unchanged $(7 \cdot 05 \mathrm{MJ})$.

The mean intake of total fat as a percentage of the food energy intake was 35.8 for men, approaching the DRV of 35 , and 34.9 for women, meeting the DRV. The mean fat intake was lower than that in the 1986-7 survey of adults, in which $>40 \%$ of the food energy was derived from fat. The range of intakes was wide, from under one-quarter of the energy derived from fat at the lower $2 \cdot 5$ th percentile to approximately half at the upper $2 \cdot 5$ th percentile. The mean intake of saturated fatty acids was $13.4 \%$ of the food energy for men and $13.2 \%$ for women, in excess of the DRV $(11 \%)$. The mean intake had fallen from $16.5 \%$ of the food energy for men and $17.0 \%$ for women in the 1986-7 survey of adults. The saturated fatty acid intakes at the lower $2 \cdot 5$ th percentile were $7-8 \%$ of the food energy, while at the upper $2 \cdot 5$ th percentile one-fifth of the food energy was derived from saturated fatty acids. The main source of fat in the diet was meat and meat products, providing approximately one-quarter of the average intake, followed by cereals and cereal products at one-fifth of the average intake. Milk and milk products and meat and meat products were the two main sources of saturated fatty acid intake, each of these sources providing approximately onequarter of the average intake.

The percentage of food energy derived from total carbohydrate was 47.7 for men and 48.5 for women, close to the DRV of 50 and higher than in the 1986-7 survey ( $44 \cdot 7$ for men and $44 \cdot 2$ for women). Intakes ranged from approximately one-third of the food energy at the lower $2 \cdot 5$ th percentile to $60 \%$ of the food energy at the upper $2 \cdot 5$ th percentile. The percentage of food energy derived from non-milk extrinsic sugars was 13.6 for men and 11.9 for women, in excess of the DRV of 11. The range of intakes was extremely wide. Non-milk extrinsic sugar intakes at the lower $2 \cdot 5$ th percentile were $2-3 \%$ of the food energy, while at the upper $2 \cdot 5$ th percentile approximately $30 \%$ of the energy was derived from non-milk extrinsic sugars. In the youngest age-group (19-24 years) men derived on

Table 1. Mean daily energy intakes and percentage contribution of macronutrients to energy intake for the 1724 respondents in the British National Diet and Nutrition Survey 2000-1

\begin{tabular}{|c|c|c|c|c|c|c|c|c|c|c|}
\hline \multirow[b]{2}{*}{ Macronutrient } & \multicolumn{4}{|c|}{ Men aged (years) } & \multirow[b]{2}{*}{ All men } & \multicolumn{4}{|c|}{ Women aged (years) } & \multirow[b]{2}{*}{ All women } \\
\hline & $19-24$ & $25-34$ & $35-49$ & $50-64$ & & $19-24$ & $25-34$ & $35-49$ & $50-64$ & \\
\hline \multicolumn{11}{|c|}{ Mean daily total energy intake: } \\
\hline MJ & $9 \cdot 44$ & $9 \cdot 82$ & $9 \cdot 93$ & $9 \cdot 55$ & $9 \cdot 72$ & $7 \cdot 00$ & $6 \cdot 61$ & 6.96 & $6 \cdot 91$ & $6 \cdot 87$ \\
\hline$\%$ EAR & 89 & 93 & 94 & 92 & 92 & 86 & 82 & 86 & 87 & 85 \\
\hline \multicolumn{11}{|c|}{ Percentage food energy from: } \\
\hline Total carbohydrate & $49 \cdot 0$ & $47 \cdot 7$ & $47 \cdot 5$ & $47 \cdot 4$ & $47 \cdot 7$ & $49 \cdot 1$ & $48 \cdot 7$ & $48 \cdot 6$ & $48 \cdot 1$ & $48 \cdot 5$ \\
\hline NMES & $17 \cdot 4$ & $13 \cdot 9$ & $13 \cdot 1$ & $12 \cdot 2$ & $13 \cdot 6$ & $14 \cdot 2$ & $11 \cdot 8$ & $11 \cdot 8$ & $11 \cdot 0$ & $11 \cdot 9$ \\
\hline Protein & $14 \cdot 9$ & $16 \cdot 5$ & $16 \cdot 7$ & $17 \cdot 0$ & $16 \cdot 5$ & $15 \cdot 4$ & $15 \cdot 9$ & $16 \cdot 7$ & $17 \cdot 4$ & $16 \cdot 6$ \\
\hline Total fat & $36 \cdot 0$ & $35 \cdot 8$ & $35 \cdot 9$ & $35 \cdot 6$ & $35 \cdot 8$ & $35 \cdot 5$ & $35 \cdot 4$ & $34 \cdot 7$ & $34 \cdot 5$ & 34.9 \\
\hline Saturated fatty acids & $13 \cdot 5$ & $13 \cdot 2$ & $13 \cdot 5$ & $13 \cdot 4$ & $13 \cdot 4$ & $12 \cdot 9$ & $13 \cdot 2$ & $13 \cdot 2$ & $13 \cdot 3$ & $13 \cdot 2$ \\
\hline Trans-fatty acids & $1 \cdot 2$ & $1 \cdot 2$ & $1 \cdot 2$ & $1 \cdot 2$ & $1 \cdot 2$ & $1 \cdot 1$ & $1 \cdot 1$ & $1 \cdot 2$ & $1 \cdot 2$ & $1 \cdot 2$ \\
\hline Cis-MUFA & $12 \cdot 4$ & $12 \cdot 3$ & $12 \cdot 0$ & $11 \cdot 8$ & $12 \cdot 1$ & $12 \cdot 2$ & $11 \cdot 7$ & $11 \cdot 3$ & $11 \cdot 1$ & $11 \cdot 5$ \\
\hline Cis-n-3 PUFA & 0.9 & $1 \cdot 0$ & $1 \cdot 0$ & $1 \cdot 0$ & $1 \cdot 0$ & $1 \cdot 0$ & $1 \cdot 0$ & $1 \cdot 0$ & $1 \cdot 1$ & $1 \cdot 0$ \\
\hline Cis-n-6 PUFA & $5 \cdot 3$ & $5 \cdot 4$ & $5 \cdot 4$ & $5 \cdot 3$ & $5 \cdot 4$ & $5 \cdot 6$ & $5 \cdot 6$ & $5 \cdot 3$ & $5 \cdot 0$ & $5 \cdot 3$ \\
\hline No. of subjects per group & 108 & 219 & 253 & 253 & 833 & 104 & 210 & 318 & 259 & 891 \\
\hline
\end{tabular}

EAR, estimated average requirement; NMES, non-milk extrinsic sugar. 
average $17 \cdot 4 \%$ of the food energy intake from non-milk extrinsic sugars, and women $14.2 \%$. Women in the oldest group (50-64 years) met the DRV, deriving on average $11.0 \%$ of their food energy from non-milk extrinsic sugars, while men derived $12.2 \%$. The main sources of non-milk extrinsic sugars for the group as a whole were table sugar (19\% of the average intake), soft drinks (16\% of the average intake) and biscuits, buns, cakes and pastries (11\% of the average intake). For the youngest group (19-24 years) the main source was soft drinks (mainly carbonated), which contributed $37 \%$ of the average intake.

The mean intake of NSP was $15.2 \mathrm{~g} / \mathrm{d}$ for men and $12.6 \mathrm{~g} / \mathrm{d}$ for women, well below the DRV of $18 \mathrm{~g} / \mathrm{d}$. Intakes ranged from 6.2 and $5.0 \mathrm{~g} / \mathrm{d}$ respectively for men and women at the lower $2 \cdot 5$ th percentile to $28 \cdot 9$ and $24.2 \mathrm{~g} / \mathrm{d}$ respectively at the upper $2 \cdot 5$ th percentile.

\section{Alcohol intake}

The percentage of the total energy derived from alcohol, excluding those who did not consume alcohol in the survey week (non-consumers), was $8 \cdot 1$ for men and $5 \cdot 7$ for women. At the upper $2 \cdot 5$ th percentile the percentage of energy derived from alcohol for consumers only was $25 \cdot 8$ for men and 18.9 for women. There were no age differences. Current advice for adults is that men should drink $\leq 3-4$ units alcohol/d and women $\leq 2-3$ units alcohol/d. Consistently drinking $\geq 4$ units alcohol/d for men or $\geq 3$ units alcohol/d for women is not advised as a sensible level because of the progressive health risk it carries (Department of Health, 1996). Of the men and women 60 and $44 \%$ respectively exceeded the recommended daily benchmarks for alcohol consumption, on at least one of the seven dietary-record days and $3 \%$ of the men exceeded them on all $7 \mathrm{~d}$. On their heaviest drinking day $39 \%$ of the men and $22 \%$ of the women drank more than twice the recommended daily benchmarks.

\section{Micronutrient intakes}

Table 2 presents the mean daily intakes of vitamins and minerals from food sources (i.e. excluding dietary supplements) as a percentage of the reference nutrient intake (RNI) and the percentage of respondents with intakes below the lower RNI (LRNI) for each age-group and gender group.

The mean intakes of all vitamins were above the RNI for men and women overall (taking all ages together). However, there was some evidence of low intakes of vitamin A and riboflavin in the younger age-groups (19-24 and 25-34 years). The mean intakes of vitamin A fell below the RNI for the youngest men and the two younger groups of women. Of the men and women 16 and $19 \%$ respectively in the youngest age-group had intakes below the LRNI. The main sources of vitamin A were meat and meat products and vegetables. The mean riboflavin intakes were above the RNI in all age-groups and gender groups, but intakes below the LRNI were found in 8 and $15 \%$ of the youngest men and women respectively and in $10 \%$ of women aged 25-34 years. The main sources of riboflavin were milk and milk products and cereals and cereal products (mainly from fortified breakfast cereals). The mean intakes of other vitamins were well above the RNI and the percentage with intakes below the LRNI was low.

The mean intakes of most minerals were above the RNI for men and women overall (taking all ages together). However, there was evidence of low intakes of a number of minerals, including $\mathrm{Fe}, \mathrm{K}, \mathrm{Mg}, \mathrm{Ca}, \mathrm{Zn}, \mathrm{Cu}$ and $\mathrm{I}$, especially in the younger age-groups.

The mean Fe intakes in women were well below the RNI in all but the oldest group, and in the two younger groups (19-24 and 25-34 years) $>40 \%$ had intakes below the LRNI. Cereals and cereal products were the main food source of Fe, providing $>40 \%$ of the average intake. On average less than one-fifth of the $\mathrm{Fe}$ intake came from meat and meat products for the group as a whole.

The mean $\mathrm{K}$ intakes for men were slightly below the RNI and for women well below the RNI, at $76 \%$ of the RNI. For men K intakes below the LRNI were found in $6 \%$ overall, increasing to $18 \%$ in the 19-24 year agegroup. For women $19 \%$ had low intakes overall, increasing to $30 \%$ in the 19-24 and 25-34 years age-groups. Potatoes and savoury snacks, meat and meat products, milk and milk products, cereals and cereal products and drinks all provided on average $>10 \%$ of the $\mathrm{K}$ intake.

The mean intakes of $\mathrm{Mg}$ for men as a group were above the RNI but for women fell below the RNI ( $85 \%$ of the RNI). Of the men and women 9 and $13 \%$ respectively had intakes below the LRNI, increasing to $17 \%$ of the men aged 19-24 years and approximately one-fifth of women in the 19-24 and 25-34 years age-groups. Cereals and cereal products were the main source of $\mathrm{Mg}$, providing $27 \%$ of the intake, followed by drinks, which provided $20 \%$ of the intake for men (half from beer and lager) and $13 \%$ of the intake for women. Meat and meat products, milk and milk products and potatoes and savoury snacks all provided on average approximately $10 \%$ of the $\mathrm{Mg}$ intake.

The youngest group of women had a mean $\mathrm{Ca}$ intake just below the RNI and $5 \%$ of the men and $8 \%$ of the women in the youngest group had intakes below the LRNI. Milk and milk products provided $>40 \%$ of the average intake, and for cereals and cereal products the contribution was $30 \%$.

The mean intakes of $\mathrm{Zn}$ fell just below the RNI for the youngest men and younger women and low intakes were seen in 7 and $5 \%$ of the youngest men and women respectively (19-24 years). For the group as a whole about one-third of the intake came from meat and meat products, one-quarter from cereals and cereal products and one-sixth from milk and milk products.

The mean I intakes fell below the RNI for the youngest women (93\% of RNI); $12 \%$ of this group had intakes below the LRNI. Milk and milk products provided $>40 \%$ of the intake for women.

The mean $\mathrm{Cu}$ intakes fell below the RNI for women in all age-groups and the youngest men. The youngest women had a mean intake of $76 \%$ of the RNI. For the group as a whole approximately one-third of the intake came from cereals and cereal products and one-sixth came from meat and meat products.

Comparisons of assessed intakes of vitamins and minerals between surveys are affected by a number of 
Micronutrient interactions and public health

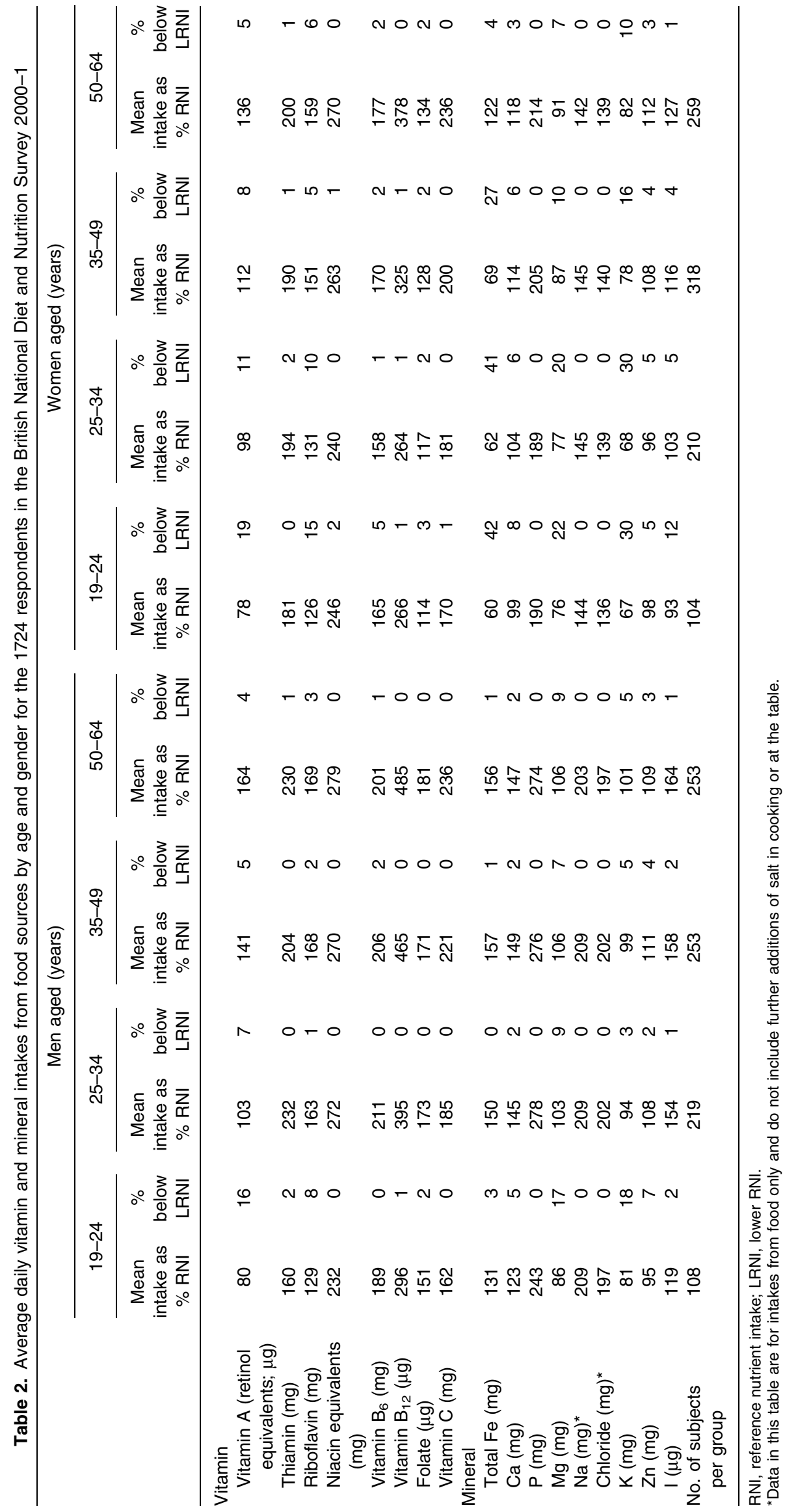


factors in addition to changes in dietary patterns, including changes in nutrient composition as a result of new varieties, increased fortification practices and new analytical methods. The mean intakes of some vitamins and minerals were higher in this survey than in 1986-7, including thiamin, niacin equivalents, vitamin $\mathrm{B}_{6}$, folate, pantothenic acid, vitamin $\mathrm{C}$, vitamin $\mathrm{E}, \mathrm{Ca}, \mathrm{K}$ and $\mathrm{P}$. Some of the increases are a result of increased fortification practices, particularly of breakfast cereals. Changes in intakes of other micronutrients are related to changes in composition data; for example, measurable amounts of vitamin $\mathrm{D}$ were found in meat and poultry in the mid1990s, and retinol composition values for liver and milk were revised downwards in the 1990s.

\section{Dietary supplements}

Of the women and men overall 40 and $29 \%$ respectively reported taking dietary supplements in the survey week. This percentage increased to 55 for the oldest women. Cod liver oil and other fish oil-based supplements and multivitamins and multi-minerals were the most popular types. Dietary supplements increased the mean intakes of most vitamins and some minerals $(\mathrm{Fe}, \mathrm{Zn}, \mathrm{Ca})$, particularly in older women. However, supplements had little or no impact on the proportions of the survey population with intakes below the LRNI, suggesting that those taking supplements had adequate micronutrient intakes from food.

The Department of Health (2000) recommend that women who could become pregnant take a supplement of $400 \mu \mathrm{g}$ folic acid/d before conception and until the 12th week of pregnancy in order to minimise the risk of neuraltube defects. The mean intake of folate from food sources was well above the RNI and only $2 \%$ of women had intakes below the LRNI. However, $86 \%$ of the women aged 19-24 years, 92\% of the 25-34 years age-group and $84 \%$ of the 35-49 years age-group had folate intakes from all sources, including the contribution of supplements, of $<400 \mu \mathrm{g} / \mathrm{d}$.

\section{Sodium}

The main reason for measuring urinary $\mathrm{Na}$ excretion was to provide an indirect estimate of $\mathrm{Na}$ intake. The mean urinary $\mathrm{Na}$ excretion per $24 \mathrm{~h}$ was $187.4 \mathrm{mmol} / \mathrm{d}$ for the men and $138.5 \mathrm{mmol} / \mathrm{d}$ for the women. These values are equivalent to estimated mean salt intakes of $11.0 \mathrm{~g} / \mathrm{d}$ for men and $8.1 \mathrm{~g} / \mathrm{d}$ for women $(9.5 \mathrm{~g} / \mathrm{d}$ overall), a slight increase on $9.0 \mathrm{~g} / \mathrm{d}$ in the $1986-7$ adults survey. The mean intakes in all age-groups and gender groups were well above the Committee on Medical Aspects of Health Policy recommendation of $6 \mathrm{~g} / \mathrm{d}$ (Department of Health, 1994), which has been endorsed by the Scientific Advisory Committee on Nutrition (2003) in its recent report Salt and Health. Of the men and women 15 and $31 \%$ respectively had average salt intakes of $\leq 6 \mathrm{~g} / \mathrm{d}$ over the survey week. The mean $\mathrm{Na}$ intakes from food, based on data from the $7 \mathrm{~d}$ weighed-intake dietary record, but excluding discretionary salt, were $3320 \mathrm{mg} / \mathrm{d}$ for men (equivalent to $8.3 \mathrm{~g}$ salt/d) and $2303 \mathrm{mg} / \mathrm{d}$ for women $(5 \cdot 8 \mathrm{~g} \mathrm{salt} / \mathrm{d})$.

\section{Physical measurements}

One in four men $(25 \%)$ and one in five women $(20 \%)$ were obese $\left(\right.$ BMI $\left.>30 \mathrm{~kg} / \mathrm{m}^{2}\right)$. A further $42 \%$ of the men and $32 \%$ of the women were overweight (BMI between $25 \mathrm{~kg} / \mathrm{m}^{2}$ and $30 \mathrm{~kg} / \mathrm{m}^{2}$ ). Overweight and obesity was more prevalent in the oldest group (50-64 years) than in the younger groups. Of the men and women aged 50-64 years 78 and $64 \%$ respectively in this group were overweight or obese. The prevalence of obesity had increased from $8 \%$ of the men and $12 \%$ of the women in the 1986-7 survey of adults. This finding is in line with those from other surveys (Department of Health, 2002b). Of the men and women 1 and $3 \%$ respectively overall were underweight (based on a BMI of $\leq 18.5 \mathrm{~kg} / \mathrm{m}^{2}$ ), increasing to $7 \%$ of the women in the 19-24 years age-group. Approximately one-quarter of the men $(23 \%)$ and $15 \%$ of the women had a waist:hip circumference ratio above the guideline thresholds for increased health risk (0.95 for men and 0.85 for women; US Department of Agriculture, 1990).

Based on measurements of systolic blood pressure, over one-fifth of the men $(22 \%)$ and $13 \%$ of the women were hypertensive according to WHO guidelines (systolic pressure $\geq 140 \mathrm{mmHg}$; Ramsay et al. 1999). The percentages of the men and women who had hypertension increased with age. In the oldest group (50-64 years) $37 \%$ of the men and $33 \%$ of the women were hypertensive.

\section{Nutritional status}

The results of the analysis of nutritional status indices in the blood samples indicated that the majority of adults were adequately nourished, with indices for most nutrients within normal ranges. However, for a few nutrients, in particular vitamin $\mathrm{D}$, also for vitamin $\mathrm{C}$, and for women, Fe and folate, a proportion had levels below thresholds for poor status.

Of the men and women 3 and $8 \%$ respectively overall had $\mathrm{Hb}$ levels below the World Health Organization (1972) thresholds defining anaemia $(130 \mathrm{~g} / 1$ for men and $120 \mathrm{~g} / 1$ for women). There was no evidence of an age trend. Of the women and men 11 and $4 \%$ respectively had serum ferritin levels below the normal range $(20-300 \mu \mathrm{g} / \mathrm{l}$ for men and $15-150 \mu \mathrm{g} / \mathrm{l}$ for women) indicating low Fe stores (Dacie \& Lewis, 2001), increasing to $16 \%$ of the women in the 19-24 years age-group.

Low vitamin D levels were found in a substantial proportion of the blood samples, particularly those for the youngest age-group and those taken in the winter months. Levels of plasma 25 -hydroxyvitamin $\mathrm{D}<25 \mathrm{nmol} / \mathrm{l}$, the threshold used to indicate low vitamin D status (Department of Health, 1998), were found in $14 \%$ of the men and $15 \%$ of the women. In the youngest group $24 \%$ of the men and $28 \%$ of the women had levels $<25 \mathrm{nmol} / \mathrm{l}$. The proportion with low status was higher in the winter months (January-March) than in the summer months (JulySeptember). Approximately one-quarter of the blood samples collected in January-March were $<25 \mathrm{nmol} / 1$.

Of the men and women $5 \%$ had an erythrocyte folate concentration $<350 \mathrm{nmol} / \mathrm{l}$, indicative of marginal status with increased risk of deficiency (Sauberlich et al. 1974), 
which increased to $8 \%$ of the women and $13 \%$ of the men in the 19-24 year group. For all age-groups and gender groups $\leq 1 \%$ had an erythrocyte folate concentration indicating severe deficiency $(<230 \mathrm{nmol} / \mathrm{l})$.

Of the men and women 5 and $3 \%$ respectively had plasma vitamin $\mathrm{C}$ levels indicating biochemical depletion (<11 $\mu \mathrm{mol} / \mathrm{l}$; Sauberlich, 1971).

It is generally accepted that a plasma total cholesterol concentration $<5 \cdot 2 \mathrm{~mol} / \mathrm{l}$ represents an optimal level, $5 \cdot 2-$ $6.5 \mathrm{mmol} / \mathrm{l}$ is mildly elevated, $6 \cdot 5-7.8 \mathrm{mmol} / \mathrm{l}$ is moderately elevated and $>7.8 \mathrm{mmol} / \mathrm{l}$ is a severely-elevated level (British Cardiac Society, British Hyperlipidaemia Association \& British Hypertension Society, 1998). Approximately half $(48 \%)$ the men and women overall had blood levels of total cholesterol above the optimal level, increasing to $59 \%$ of the men and $75 \%$ of the women in the oldest group (50-64 years). Over one-third of the group as a whole had mildly-elevated levels, approximately one in ten had moderately-elevated levels and $2 \%$ of the men and $3 \%$ of the women had severely-elevated levels.

\section{Physical activity}

Based on information from the $7 \mathrm{~d}$ physical activity diary, approximately one-third of the men $(36 \%)$ and about onequarter of the women $(26 \%)$ met the current Department of Health recommendation on physical activity for adults of at least $30 \mathrm{~min}$ of physical activity of at least moderate intensity on $\geq 5 \mathrm{~d} /$ week (Blair \& Connelly, 1995). One in six individuals did not record any time spent in activities of at least moderate intensity over the $7 \mathrm{~d}$ period. However, when interviewed, about half those who took part in the survey said that they were fairly physically active and a further one-fifth said they were very physically active.

\section{Adults in households in receipt of benefits}

Adults living in households in which someone was receiving state benefits generally had poorer diets than those in non-benefit households. There was also some evidence of poorer nutritional status in this group.

Adults living in benefit households consumed fewer portions of fruit and vegetables, on average $2 \cdot 1$ portions per $\mathrm{d}$ for men and 1.9 portions per $\mathrm{d}$ for women, compared with $2 \cdot 8$ and $3 \cdot 1$ portions per $d$ respectively for men and women in non-benefit households. Of the men and women 35 and $30 \%$ respectively in benefit households ate no fruit during the $7 \mathrm{~d}$ recording period, compared with 19 and $12 \%$ respectively in non-benefit households. A much smaller percentage ate no vegetables during the same period $(4 \%$ of the men and $6 \%$ of the women in benefit households compared with $2 \%$ of the men and $1 \%$ of the women in non-benefit households).

Men and women in benefit households had lower mean energy intakes than those in non-benefit households, and thus absolute intakes of some macronutrients were also lower for this group. Women in benefit households derived a higher percentage of their energy intake from non-milk extrinsic sugars and a lower percentage from protein than did women in non-benefit households. There was no difference between the benefit and non-benefit groups in the percentage energy derived from fat or fatty acids.

Those in benefit households were less likely to have recorded consuming alcohol during the dietary recording period than those in non-benefit households. For those who consumed alcohol there was no difference in mean intake between adults in benefit and non-benefit households.

Individuals in benefit households had lower mean daily intakes of the majority of vitamins and almost all minerals compared with those in non-benefit households. Compared with the non-benefit group a higher percentage of the benefit group had intakes of some vitamins and many minerals that were below the LRNI; for example, $22 \%$ of the women in the benefit group had low intakes of vitamin A, $19 \%$ had low intakes of riboflavin, $27 \%$ had low intakes of $\mathrm{Mg}$ and $34 \%$ had low intakes of $\mathrm{K}$. Over half the women aged 19-50 years in the benefit group had Fe intakes below the LRNI compared with about one-third of the women in non-benefit households.

There was some evidence of a lower micronutrient status for the benefit group. For men and women living in benefit households mean levels for vitamin $\mathrm{C}$, erythrocyte, folate, vitamin $\mathrm{E}$ and $\mathrm{Se}$, and for women mean levels of carotenoids and vitamin D, were lower than those for nonbenefit groups. There was no difference in mean blood lipid levels between the benefit and non-benefit groups.

There was no difference in mean BMI between the benefit and non-benefit groups. However, women in benefit households had a higher mean waist:hip circumference than those in non-benefit households. There was no difference in physical activity levels between the benefit and non-benefit groups.

\section{Regional differences}

The results showed very few regional differences in food consumption, nutrient intakes or nutritional status indices and no consistent patterns.

\section{Summary}

This survey of 1724 British adults aged 19-64 years has found that, while mean fat intake in this group is close to the UK DRV, mean intakes of saturated fat and non-milk extrinsic sugars exceed the DRV. Mean salt intake is also higher than the recommended intake. Taking the age-group as a whole, mean intakes of most vitamins and minerals are above the RNI, but intakes fall below the LRNI for a substantial proportion of younger adults, particularly young women. This group also has lower levels for some indices of micronutrient status. Fruit and vegetable consumption is on average less than three portions daily. One in four men and one in five women are obese and the physical activity levels of the majority of participants are lower than recommended levels.

\section{Acknowledgements}

The National Diet and Nutrition Survey of adults aged 19-64 years was funded by the Food Standards Agency 
and the Department of Health and carried out by the Office for National Statistics and the Medical Research Council Human Nutrition Research. The author would like to acknowledge the authors of the published reports: Lynne Henderson, Jan Gregory, Karen Irving, Dave Ruston and Jackie Hoare of the Office for National Statistics; Dr Chris Bates, Dr Ann Prentice, Dr Maureen Birch and Dr Jayne Perks of the MRC Human Nutrition Research and Melanie Farron of the Food Standards Agency.

\section{References}

Blair SN \& Connelly JC (1995) How much physical activity should we do? The case for moderate amounts and intensities of physical activity. In Moving On: International Perspectives on Promoting Physical Activity, pp. 18-34 [AJ Killoran, P Fenten and C Caspersen, editors]. London: Health Education Authority.

British Cardiac Society, British Hyperlipidaemia Association \& British Hypertension Society (1998) Joint British recommendations on prevention of coronary heart disease in clinical practice. British Cardiac Society, British Hyperlipidaemia Association, British Hypertension Society, endorsed by British Diabetic Association. Heart 80, Suppl. 2, S1-S29.

Dacie JV \& Lewis SM (2001) Practical Haematology, 9th ed. Edinburgh: Churchill Livingstone.

Department of Health (1991) Dietary Reference Values for Food Energy and Nutrients for the United Kingdom. Report on Health and Social Subjects no. 41. London: H.M. Stationery Office.

Department of Health (1994) Nutritional Aspects of Cardiovascular Disease. Report on Health and Social Subjects no. 46. London: H.M. Stationery Office.

Department of Health (1996) Sensible Drinking - The Report of an Inter-departmental Working Group. London: H.M. Stationery Office.

Department of Health (1998) Nutrition and Bone Health with Particular Reference to Calcium and Vitamin D. Report on Health and Social Subjects no. 49. London: The Stationery Office.

Department of Health (2000) Folic Acid and the Prevention of Disease. Report on Health and Social Subjects no. 50. London: The Stationery Office.

Department of Health (2002a) Five a day programme. http:// www.doh.gov.uk/fiveaday/

Department of Health (2002b) Health Survey for England 2001. Summary of key findings. http://www.official-documents.co.uk/ document/deps/doh/survey01/md/md.htm

Finch S, Doyle W, Lowe C, Bates CJ, Prentice A, Smithers G \& Clarke PC (1998) National Diet and Nutrition Survey: People Aged 65 Years and Over. vol. 1: Report of the Diet and Nutrition Survey. London: The Stationery Office.

Food Standards Agency (2004) Your daily diet. Meat, fish, eggs and pulses. http://www.food.gov.uk/healthiereating/dailydiet/ meatfisheggs/
Gregory J, Foster K, Tyler H \& Wiseman M (1990) The Dietary and Nutritional Survey of British Adults. London: H.M. Stationery Office.

Gregory JR, Collins DL, Davies PSW, Hughes JM \& Clarke PC (1995) National Diet and Nutrition Survey: Children Aged 11/2 to 41/2 Years. vol. 1: Report of the Diet and Nutrition Survey. London: H.M. Stationery Office.

Gregory J, Lowe S, Bates CJ, Prentice A, Jackson LV, Smithers G, Wenlock R \& Farron M (2000) National Diet and Nutrition Survey: Young People Aged 4 to 18 Years. vol. 1: Report of the Diet and Nutrition Survey. London: The Stationery Office.

Henderson L, Gregory J, Irving K \& Swan G (2003a) The National Diet and Nutrition Survey: Adults Aged 19 to 64 Years. vol. 2: Energy, Protein, Carbohydrate, Fat and Alcohol Intake. London: The Stationery Office.

Henderson L, Gregory J \& Swan G (2002) The National Diet and Nutrition Survey: Adults Aged 19 to 64 Years. vol. 1: Types and Quantities of Foods Consumed. London: The Stationery Office.

Henderson L, Irving K, Gregory J, Bates CJ, Prentice A, Perks J, Swan G \& Farron M (2003b) The National Diet and Nutrition Survey: Adults Aged 19 to 64 Years. vol. 3: Vitamin and Mineral Intake and Urinary Analytes. London: The Stationery Office.

Office for National Statistics (2002) Feasibility study report: NDNS adults aged 19-64 years. In National Diet and Nutrition Survey: Adults Aged 19-64 Years. Technical Report. Appendix $C$; available at: http://www.food.gov.uk/science/101717/ ndnsdocuments/ndnsappendices

Ramsay LE, Williams B, Johnston DG, MacGregor GA, Poston L, Potter JF, Poulter NR \& Russell G (1999) Guidelines for management of hypertension: report of the third working party of the British Hypertension Society. Journal of Human Hypertension 13, 569-592.

Ruston D, Hoare J, Henderson L, Gregory J, Bates CJ, Prentice A, Birch M, Swan G \& Farron M (2004) The National Diet and Nutrition Survey: Adults Aged 19 to 64 Years. vol. 4: Nutritional Status (Anthropometry and Blood Analytes) Blood Pressure and Physical Activity. London: The Stationery Office.

Sauberlich HE (1971) Vitamin C status: methods and findings. Annals of the New York Academy of Sciences 24, 444-454.

Sauberlich HE, Skala JH \& Dowdy RP (1974) Laboratory Tests for the Assessment of Nutritional Status. Cleveland, OH: CRC Press.

Scientific Advisory Committee on Nutrition (2003) Salt and Health. London: The Stationery Office.

Skinner CJ \& Holmes D (2002) The 2000-01 National Diet and Nutrition Survey of Adults aged 19-64 years: The impact of non-response. In National Diet and Nutrition Survey Adults Aged 19-64 Years. Appendix E; available at: http://www.food. gov.uk/science/101717/ndnsdocuments/ndnsappendices

US Department of Agriculture (1990) Report of the Dietary Guidelines Advisory Committee on the Dietary Guidelines for Americans. Washington, DC: USDA/HNIS.

World Health Organization (1972) Nutritional Anaemias. Technical Report Series no. 503. Geneva: WHO. 